\title{
FEIJÓO Y SU PAPEL DE DESENGAÑADOR DE LAS ESPAÑAS
}

Según cuenta su contemporáneo Lanz de Casafonda era Feijóo "venerado por un Oráculo en toda España y en las Indias". El P. Sarmiento habla, refiriéndose al Teatro crítico, de "la universal aceptación que tiene esta excelente obra" ${ }^{1}$. El número mismo de las ediciones del Teatro y de las Cartas eruditas atestiguan el extraordinario éxito de los escritos del benedictino. Aun más significativo a este respecto, como ejemplo concreto de la difusión de sus ideas, es el que se hiciera un índice general de su obra, y que luego fuera éste ampliado y transformado en diccionario. En efecto, en I 774, en Madrid, publica José Santos un Indice General Alfabético De Las Cosas Más Notables Que Contienen Las Obras De Feijóo. Y en 1802, también en Madrid, Antonio Marques Y EsPejo publicará el Diccionario feijoiano. Y dato todavía más curioso: en tiempo de Carlos III se publicó en Madrid una revista titulada Feyjóo Crítico Moral y Reflexivo de su Teatro, Sobre Errores Comunes ${ }^{2}$. No hay pues que situar a Feijóo como espléndida figura solitaria que se yergue rebelde en medio de la ignorancia y la indiferencia de sus con-

el de Ledel arriba, pág. ıo, y el de Sotomayor, pág. 27ı. El texto de Liaño sobre la $\varsigma$ y la $z$ que reproducimos en esta $N R F H, \mathrm{~V}$, pág. Io, es el de Barcelona. Y al plagario Liaño plagia el de Barcelona igualmente para las otras cuatro letras que explica, con su $c h$ española igual que la francesa, y, lo que es más, con la $j$ española igual que la $j$ francesa, sin importarle al confeccionador de 1647 que la $j$ española fuera ya sorda y velar, a la moderna, desde hacía medio siglo (descripciones independientes del francés César Oudin ${ }^{1597}$, del inglés Lewis Owen I605, y del alemán Kaspar Schoppe 1613). Después de explicar la pronunciación española con el texto de Liaño, la vuelve a tratar por entero con el de Sotomayor, plagiando al plagiario de Meurier, no sólo en lo que nosotros reproducimos arriba de las sibilantes, págs. 270-27 I, sino en todo lo demás, empezando por el título de la sección y continuando con sus mismas descripciones, cuadros, llaves, ejemplos y su extraña nomenclatura ("Pronunciaciones equipolentes y equivalentes", etc.). Donde Sotomayor traduce a Meurier, el de Barcelona pone el texto español, y donde Sotomayor lo deja en francés, en francés lo deja el de Barcelona.

1 Lanz de Casafonda, Del estado presente de la literatura de España, Semanario del Valladares, XXVIII, pág. I45. SARMIEnto, Demonstración crítica-apologética del Theatro crítico universal, Pamplona, 1787 , pág. $\mathrm{xx}$.

2 El autor de la revista era Leonardo Antonio de la Cuesta, y fué publicada en tiempo de Carlos III. No sabemos en qué años, ni cuánto duró. Véase, SEMPERE y GuARINos, Ensayo, IV, pág. 187. 
temporáneos. Su fama inmediata, el número infinito de sus lectores prueban que tuvo su obra una resonancia sin igual.

Quince años ha que estoy continuamente declamando contra la fatua credulidad que reyna en el mundo; y pienso que el mundo, a la reserva de pocos individuos, en quanto a esta parte, se está como se estaba. Todos oyen mis voces y casi todos que parece están sordos a ellas ${ }^{3}$.

Estas palabras nos ponen de manifiesto el móvil grandioso de su empresa literaria y los efectos de su acción espiritual. Todos oyen mis voces, nos dice, consciente del éxito alcanzado, mas con un tono quejumbroso motivado por su creencia en el poder de la palabra. ¿A qué más puede aspirar un escritor sino a que se le oiga? Y Feijóo fué, efectivamente, oído por todos. No nos dejemos engañar por su postura altanera en lo que respecta al estado cultural de España. La avidez con que se le leyó prueba que se le esperaba, y, pese a su sentimiento de fracaso, produjo su obra un cambio indudable en el clima espiritual del mundo hispánico. Pensemos en la influencia ejercida por Ortega y Gasset en nuestros días y se nos aclarará la supuesta pretensión de Feijóo de haber predicado en el desierto. La postura suya de combatir al vulgo tiene, además, significación literaria en sí misma. Aparte de los efectos prácticos de sus prédicas, lo que Feijóo logra es inventarse a sí mismo. Como Guevara, como Montaigne, como Azorín, Feijóo crea un personaje literario único, se crea a sí mismo, Fray Benito, el Desengañador de las Españas. Feijóo hablará de cómo hacer historia, de cómo se debe filosofar, de que se debe cultivar la ciencia experimental, pero no será historiador, ni filósofo, ni hombre de ciencia. Y es que lo esencial en él, literariamente, es el impulso personalizante. No podía limitarse, como hicieron los grandes eruditos españoles de su época, a aspectos parciales del saber humano, puesto que su intento literario le hacía forzoso abarcar el ámbito total de la cultura.

\section{GESTO SEÑORIAL Y AFÁN INDIVIDUALIZANTE}

La grandiosidad de su impulso es muy semejante, en magnitud ambiciosa, a la de un conquistador de nuevas tierras. El mismo se equipara a los conquistadores hispánicos, y nos da la clave de su móvil literario en la dedicatoria del cuarto tomo de las Cartas eruditas y curiosas, dedicado a la reina de España, doña María de Portugal. Al referirse al éxito que han tenido sus obras en Portugal, escribe:

3 Cartas eruditas y curiosas, I, xxxv, 8. Abreviaturas en adelante: T., Teatro critico; C., Cartas eruditas. Subrayado nuestro en todos los textos de Feijóo citados en este escrito. 
Bien comprehendo, Señora, que en esta benevolencia que debo a la Nación Portuguesa, no debo contar por mérito mío lo que es generosidad suya. Acaso algunos la imaginaran pasión nacional; porque habiendo yo nacido en los últimos confines de Galicia, hacia Portugal, es fácil equivocar la qualidad de vecino con la de paysano. Mas como nadie es capaz de poner prisiones a la imaginación no pude atajar el arrojado vuelo que tomó la mía a buscar otra causa; que, a ser bien verificada, altamente lisonjearía mi amor propio. Acaso (¿qué sé yo?) me ganó el afecto de aquella animosa Nación haber reconocido en mi rumbo literario cierta imitación de genio: de aquel genio, digo, cuyo elástico impulso naturalmente rompe hacia empresas altas y peligrosas; de aquel orgullo arrogante, que, no cabiendo dentro de todo el mundo conocido, se ensanchó por millares de leguas al Oriente, y al Poniente, a una y otra India: de aquel noble aliento, que dió a una Provincia la conquista de tantas Provincias por medio de tantos Héroes, que divididos, pudieran ilustrar muchos Reynos, quales fueron los $\mathrm{Ga}$ mas, los Almeydas, los Alburquerques, los Castros, los Pachecos, los Sylveiras, los Magallanes, y otros, cuya fama durará cuanto dure el mundo.

Acaso (vuelvo a decir) me captó la benevolencia de los señores Portugueses contemplar en alguna manera imitada en mi proyecto de impugnar errores comunes la magnanimidad de aquellos ilustres Conquistadores; pues no podían mirar mi empresa sino como extremadamente ardua, extraordinaria, peligrosa. Combatir errores envejecidos, es lidiar con unos tan raros monstruos, que, en vez de debilitarlos la senectud, les aumenta el vigor. La qualidad de comunes desde luego hacía ver que había de armar contra mí una multitud inmensa de enemigos, como, de hecho, desde los principios se vieron cubiertas de ellos las campañas, que apenas me quedaron, o como favorables, o como indiferentes, la décima parte de los mortales. $\mathrm{Y}$ aun este número se me acortó mucho más, luego que me vieron en el empeño de establecer la igualdad intelectual de los dos sexos; vindicando el amable y débil de la injuria, que generalmente se le hacía en negarle esta igualdad. $O$, quántos sarcasmos me atraxo esta noble empresa! (C., IV, págs. vI-vIII.)

Estas líneas de Feijóo, aunque no sean de las más típicas suyas, revelan muy claramente los rasgos característicos de su intento literario, y son ellas mismas la expresión estilística de su impulso individualizador. Nadie es capaz de poner prisiones a la imaginación, nos dice, poniendo así de relieve no un hecho general discutible, sino una característica suya. Su imaginación, en efecto, toma un arrojado vuelo al buscar la causa de su éxito en Portugal. No es en su caso una frase retórica. Feijóo aspira a dar ritmo de acción a su estilo, ya que él se ve a sí mismo en permanente actividad conquistadora, en perpetua lucha con el mundo en torno. «Rumbo literario», la expresión que emplea para compararse a los portugueses, nos sugiere viajes y resuelto encaminamiento, pero algo 
también de rumboso, de gesto nobiliario. Al continuar la comparación, dice "rompe hacia", expresión activa clave, de impulso más que de realización. Y otro término muy significativo: "ensanchar". Feijóo quiere ensanchar el ámbito cultural de España, así como él mismo ha querido abarcar todos los conocimientos de su tiempo. Vemos además que "orgullo arrogante" forma pareja con "noble aliento". Esto, aparentemente, es retórica, ya que se dirige a la reina de España, que es portuguesa. Pero Feijóo se identifica inmediatamente con los grandes héroes portugueses, y nos parece como si se incluyera en la expresión "y otros" con que termina la enumeración de éstos. En el segundo párrafo habla ya concretamente de sí mismo. Si Feijóo se complace en escoger como término de comparación a los conquistadores portugueses se debe no sólo al paisanaje sino también quizá a ciertos rasgos de los exploradores y aventureros lusitanos. El primero que cita es Gama, el último Magallanes, navegantes los dos, hombres que abren el camino de zonas tenebrosas. $\mathrm{Y}$ lo que antes era descrito como rumbo literario es ahora empresa ardua y peligrosa. Empresa, tal como usaba la palabra en la primera parte del texto citado, significaba objetivo. Ahora es la acción misma, el combatir errores comunes. Estos son como monstruos, raros monstruos, quizá semejantes a los imaginarios monstruos marinos que no arredraron a los navegantes portugueses. Y la conciencia de esta amenaza produce en la prosa de Feijóo toda una serie de términos militares: armar, enemigos, campañas. Feijóo se ve a sí mismo en guerra de conquista espiritual contra el numeroso ejército del vulgo, y además, desde que salió el primer tomo del Teatro, se cubrieron efectivamente de enemigos muchas tierras hispánicas. Pero el saberse atacado le anima a seguir la lucha, le confirma sobre todo en su idea de que sus escritos son una fuerza liberadora. "Yo no puedo con honor abandonar tantos ignorantes", dice en otra ocasión, "entre quienes miro muchos como conquista mía, a que sobre ellos vengan a hacer correrías los partidarios de los Errores Comunes". (C., II, pág. xxxi). De nuevo expresiones y términos militares: conquista, hacer correrías. $Y$ fraternal ademán quijotesco: no puede dejar desamparados a los ignorantes. Muy al principio de su actividad literaria dirá de sí mismo que sale al campo "sin más armas que el raciocinio y la experiencia". Es, por lo tanto, una empresa literaria con aire militar. Feijóo espera, quiere que sus enemigos sean numerosos, y poderosos. Sus partidarios, en cambio, muy escasos, una décima parte de los mortales. Y pronto, nos dice en el texto citado, "este corto número se me acortó". El uso del dativo de interés expresa directamente la actitud de Feijóo respecto a sus lectores y a sus seguidores. De la misma manera que había hablado de ellos como conquista suya, ahora dirá que se $l e$ acortó el número de sus partidarios. La relación posesiva que él establece con su público es una manifestación más del impulso personalizante y del gesto señorial que le caracterizan. Frente a los genios del 
mal, frente a los Errores Comunes, agigantados por las mayúsculas, alza quijotescamente su personalidad dominadora de Desengañador.

Lo fundamental en él, lo que le ha creado literariamente, es el afán individualizante, la aspiración a relacionar, dinámica y combativąmente, la realidad circundante con su persona. El móvil literario real de Feijóo no es tanto desengañar a los españoles como explayar su personalidad por el vasto campo de los Errores Comunes. Su obra, más que un repertorio de ideas dieciochescas, es su propia novela, como lo sugirió Emilia Pardo Bazán en su magnífico ensayo sobre Feijóo. Percibió la escritora gallega que lo esencial en la obra del benedictino no es el racionalismo sino la forma en que él lo vive. $Y$ es que en definitiva las supercherías y supersticiones combatidas por Feijóo juegan, en su vida y en su obra, el mismo papel que las "soñadas invenciones" en la imaginación de Don Quijote. Su fantasía quizá, pero más aún su afán por realzar su personalidad, se recreaba con todas las creencias absurdas que él atribuía al pueblo español, pero que muchas veces sólo existían en los libros. Feijóo vió quijotescamente muchos gigantes donde no los había para poder proyectar sobre el fondo de sus sombras amenazadoras la grandiosidad señorial de su figura de Desengañador de las Españas.

\section{VOLUNTAD DE ESTILO Y HAGER LITERARIO}

El impulso personalista de Feijóo, móvil real de su empresa desengañadora, se expresa claramente también en su afán por crearse un estilo propio que le haga sobresalir entre los escritores de su tiempo. "Todos han conocido que mi estilo siempre es mío, siempre tiene un carácter que le distingue de los demás estilos", afirma Feijóo con la misma altivez con que se quejaba de la sordera espiritual de sus contemporáneos. Estas palabras suyas, como muchas de las citadas anteriormente, nos revelan sus aspiraciones personalistas. Feijóo siente, muy justamente, que el estilo es algo emanado de la persona y no de algo externo a ella. En esta actitud literaria Feijóo está completamente en la línea de escritores declaradamente anti-retóricos como Montaigne, por ejemplo. "Ni he tenido estudio, ni seguido algunas reglas para formar el estilo. Más digo, ni le he formado ni he pensado en reformarle. Tal qual es, bueno o malo, de ésta especie, u de aquella, no lo busqué yo; él se me vino; y si es bueno, como V. md. afirma, es preciso que haya sido así, como voy a probar", le escribe a uno de los supuestos corresponsales de las Cartas eruditas (C., II, vi, I ). No hay estilo, para Feijóo, sin naturalidad. El estilo para ser natural ha de ser personal, no imitado de nadie. Ha de ser la expresión literaria del carácter de la persona, y él advierte que "cada hombre tiene su carácter que le distingue, y hace distinguir por los que son dotados de algún conocimiento" (Ibid., 8). No hay en esto, por parte de Feijóo, originalidad absoluta, pero, como en el caso de Séneca, uno de los antecedentes 
suyos en este aspecto, el calor con que es expuesta la idea de la relación entre hombre y estilo es más importante que la idea en sí. Refleja en ellos su clara voluntad de estilo, su impulso hacia la propia expresión. La actitud de Feijóo le sitúa dentro de lo que llamamos senequismo literario hispánico que, inaugurado por Alonso de Cartagena y Hernán Pérez de Guzmán, representa una tradición permanente en nuestra literatura, y que consiste tanto en una reiteración secular de las mismas ideas como en una semejante actitud literaria, ligada a una voluntad de filiación. Actitud que Gracián define cuando habla de que "en España siempre hubo libertad de ingenio ... sus dos primeros ingenios, Séneca en lo juicioso y Marcial en lo agudo, fundaron esta opinión, acreditaron este gusto" (Agudeza y arte de ingenio, Discurso LI). Y añade: "Quedó vinculado este gusto ... en esta ingeniosa provincia ... y nunca más válido que en este feraz siglo, en que han florecido sus ingenios ... discurriendo todos a lo libre". El discurrir a lo libre, he aquí uno de los rasgos formales del senequismo literario hispánico que se encuentran en Feijóo. Pero, si en él desemboca esta tradición de afán por personalizar la expresión literaria, esta actitud cobra un sesgo más radical en la fundamentación suya. En efecto, su oposición a la retórica va de par con su anti-escolasticismo. Intentar escribir bien siguiendo las reglas de la preceptiva es lo mismo que tratar de razonar bien ateniéndose a las reglas sumulísticas. Para escribir bien, dice Feijóo, se necesita tener lo que él denomina tino mental, expresión que nos parece como clave de su actitud espiritual y literaria. La elección del término tino pone de manifiesto su orientación filosófica, muy dieciochesca. Toda su teoría respecto a la belleza, su admiración por los sabios ingleses, particularmente por Bacon y Boyle, su anti-escolasticismo, su anti-cartesianismo también, todo parece estar simbolizado y representado en esa expresión. Y de ahí que Feijóo no estime útil tampoco la práctica del escribir, el ejercicio literario, como conducente a forjarse un estilo propio. "Mi experiencia me hace desconfiar de este medio" (Ibid., 22). Esta frase también nos da sucintamente la imagen espiritual del benedictino gallego, confiando ante todo en su experiencia personal. $\mathrm{El}$ adjetivo posesivo que inicia la frase revela esa seguridad en sí mismo, esa desconfianza en todo lo abstracto que son sus dos características espirituales más acusadas.

Para Feijóo, escritor interesado en dar a sus palabras una intención activa, el tener tino mental significa, por otra parte, una mayor capacidad persuasiva para "mover, atentas las circunstancias, a los oyentes o lectores". Feijóo da una peculiar importancia a las circunstancias. El tino mental consistirá precisamente en sentir inmediatamente cuáles son las palabras y el tono apropiado para persuadir, para mover, al lector. De ahí que Feijóo, como Unamuno, tienda a dar a su prosa el aire cálido del lenguaje conversacional. En su elogio de la buena conversación expresa muy precisamente su actitud. 
Mejor que los mejores libros es la buena conversación. La enseñanza que se comunica por medio de la voz, es natural; la de la escritura, artificial: aquélla animada, ésta muerta; por consiguiente aquélla eficaz, y activa, ésta lánguida. La lengua escribe en la alma, como la mano en el papel. Lo que se oye es el primer traslado, que se saca de la mente del que instruye; lo que se lee, ya es copia de copia ( $T$., III, xII, 29).

Notemos la serie de ventajas de la enseñanza oral: naturalidad, eficacia, espontaneidad original. La voz es lo natural, es decir, lo personal. La exposición oral es animada, y por lo tanto efectiva. Efectiva por natural y de ahí que pueda decir Feijóo que la lengua escribe en el alma. Estas palabras suyas revelan sus constante afán por persuadir hondamente. Por esta actitud entra Feijóo también dentro de la tradición espiritual que hemos denominado senequismo literario hispánico. Para Feijóo, como para Séneca y los senequistas españoles, el tono conversacional es preferido por más personal y convincente. Por eso critica, siguiendo a Bacon, el tono magistral.

Entre los profesores de letras hay no pocos tediosos a los circunstantes porque siempre quieren hacer el papel de maestros. Para ellos todo lugar es Aula, toda silla es Cáthedra, todo oyente discípulo ... Quanto articulan sale en solfa de sentencia rotal. Su tono es siempre decisivo, su voz tiene la magestad de oráculo, su acción parece de Maestro de Capilla, que echa el compás a todo ( $T$., VII, $\mathbf{x}, 79)$.

La clave de la actitud literaria de Feijóo, en cuanto a la relación con su público, se nos revela en esa aspiración suya a ver a sus lectores cerca de él, en calidad de "circunstantes". Quiere acercarse a ellos, crear una atmósfera de cordialidad y apacibilidad. Ha de hablarles en estilo conversacional, en lenguaje que se amolde a las circunstancias y a las personas. Se le hará preciso, por ejemplo, mezclar lo festivo con lo grave según acostumbraba en su propia conversación.

La verdad, si no me engaño, es que mi conversación sigue, por lo común, la mediocridad entre jocosa y seria, lo que proviene también en parte del temperamento y en parte de la reflexión. El común comercio pide mezclar oportunamente lo festivo con lo grave (C., V, xvIr, 9).

El estilo de Feijóo es como su conversación. Es el estilo de un hombre afable de tertulia conventual, de un catedrático retirado que ya no tiene ocasión de dar animadas conferencias. Hay aún momentos profesorales, pero en general el tono es familiar, puesto que ya no es menester alzar la voz. Lo que predomina es la naturalidad, la personalidad de Feijóo. Al leer sus obras le sentimos presente en cada página, pero su estilo no es 
el de un artista del lenguaje. Al apuntar Feijóo a su público inmediato, más que al público de siempre, crea lo que Ortega y Gasset ha llamado obra operante, sin gran valor artístico. Su obra tiene aire periodístico, fisonomía de revista unipersonal. Sin embargo, como veremos a continuación, dentro del ensayismo hispánico tienen los escritos de Feijóo una gran significación. La importancia de su influencia literaria, mayor que su àrte, confiere a Feijóo un lugar especial en el desarrollo del ensayo español.

\section{PRIMER ENSAYISTA CONTEMPORÁNEO}

El escritor enciclopédico, el ensayista, se impone a la larga en Feijóo, y el quimérico Desengañador pasa a segundo plano. Piensa, a medida que avanza su obra, más y más en el agrado de sus lectores que en el quijotesco intento suyo del principio. Notamos un tono más personal, más familiar en las Cartas que en los Discursos. Los Discursos del Teatro crítico universal son, en general, auténticos ensayos. Recordemos que en la prosa española del siglo xvir se emplea con frecuencia el término discurso con la acepción de essai. Quevedo, el primero, al hablar de Montaigne se referirá a los "Essais o Discursos". Y Fray Diego de Cisneros el primer traductor español del ensayista gascón titulará muy acertadamente su traducción: Experiencias y varios discursos de Miguel, señor de Montaña $a^{4}$. El término discurso adecuadamente expresa lo discursivo del ensayo, lo que esta forma literaria tiene de "running discourse", según la definición del ensayista inglés Felltham. En los discursos de Feijóo se encuentra ese libre "discurrir" a que nos referimos antes, mas tienen mucho de sermones laicos, de homilías científicas. El tono conversacional que él aspiraba a dar a sus escritos está con frecuencia ausente. Las Cartas, en cambio, presentan rasgos más personales. Feijóo ve más concretamente a su público en éstas que en los discursos, y esto se revela en la forma misma de sus escritos. En las cartas logra dar cuerpo a las aspiraciones literarias que constituyen su voluntad de estilo. Su crítica del tono magistral, su elogio de la buena conversación, su creencia en la necesidad de mezclar lo festivo con lo grave, su afán por referir todo a su persona, se integran con mayor plenitud en las Cartas que en los Discursos. Lo importante, en aquéllas, no es tanto el impugnar errores comunes como el asombrar al público con su capacidad enciclopédica. El impulso por abarcar todo género de materias es más decisivo que el de combatir los errores comunes que se cometen en todo género de materias. Pensamos, leyéndolas, en Guevara, aunque los dos escritores sean muy distintos. En una de las Cartas se queja de que se le suponga enterado de todo, pero, ¿no quería acaso dar esa impresión? "Yo escribo de

4 La traducción de Fray Diego de Cisneros ( 1637 ) la cita Gallardo, Ensayo de una biblioteca de libros raros y curiosos, número 1838 . 
todo y no hay asunto alguno forastero al intento de mi Obra", proclama orgullosamente al afirmar la originalidad de su empresa. $\mathrm{Y}$ añade con no menos orgullo:

Oyes decir a algunos (bien que realmente dista mucho de la verdad) que gozo una amplísima erudición en todo género de materias; y nunca hubiera yo logrado este magnífico concepto, si hubiese aplicado la pluma a alguna facultad determinada ( $T$., IV, prólogo).

Este afán de explayar su personalidad por el vasto campo de una cultura enciclopédica le sitúa entre los ensayistas genuinos. En el genérico anti-sistematismo de éstos hay, sobre toḍo, una voluntad de realzar la propia personalidad, ya que toda creación objetivamente estructurada cubre la individualidad concreta del hombre y adquiere vida independiente, ya desligada de su autor.

Feijóo, por su consciente impulso enciclopédico, puede ser considerado como el primer ensayista hispánico contemporáneo. Siente que "hay que ser por fuerza enciclopedistas", según dirá Unamuno. El campo de su actividad literaria incluye aspectos de todo el saber humano. Quevedo, es cierto, ya se había distinguido como polígrafo, y Gracián abarcaba, en sus obras, una amplia zona cultural. El mismo Zabaleta se ocupa de problemas de muy diversa índole. $Y$ antes que todos ellos Luis Vives había intentado una labor enciclopédica. La originalidad de Feijóo, en relación con estos antecesores suyos, la expresa muy claramente Campomanes al compararle con Vives:

Luis Vives escribió en latín su Obra, y así fué poco leída del común de nuestros Nacionales. Con más provecho de éstos el $\mathrm{P}$. Feijóo puso en lengua vulgar las observaciones acomodadas a nuestro tiempo $(T$., I, pág. III).

Los rasgos apuntados por Campomanes precisan la situación de Feijóo dentro del ensayismo hispánico. Es un escritor más vulgar que Quevedo y que Gracián. Casi puede afirmarse que es el primer ensayista español que cuenta con un público vasto y diverso. La misma acusación que le hacían sus impugnadores de que escribía para muchos estaba bien fundada, aunque precisamente en su escribir para muchos consiste el arte suyo. Una de las características del ensayista, en general, es la de dirigirse a un público variado, aux divers visages d'un peuple, según Montaigne. Feijóo es quizá el primero de los ensayistas españoles que escribe cara al público, pensando en un vasto público. Las mismas referencias constantes al vulgo manifiestan la presencia de éste, la presencia del público en la obra de Feijóo. “Qué necesidad tiene el público, — dirá para defenderse de ciertos ataques-, de que yo escriba sobre alguna de estas facultades?" ( $T$., IV, prólogo). Para Feijóo cuen- 
tan las necesidades del público, cuenta lo que los lectores esperan y han menester. En este sentido está también en la línea de los sabios mediadores hispánicos, línea que a veces se confunde con la de los ensayistas y los senequistas. Feijóo, como Alonso de Cartagena, siente que lo que a todos cumple saber ha de ser expresado "en lengua que se entienda por todos". El obispo expresaba claramente su voluntad de estilo al decirle a Pérez de Guzmán que quería ser más llano, escribiendo "en nuestro romanze en que hablan así caualleros como omes de pie, e así los scientíficos como los que poco o nada sabemos"; y añadía: "pie a tierra... vos entiendo servir" " $\mathrm{El}$ arte de Feijóo consiste justamente en un escribir, pie a tierra, sobre temas científicos y filosóficos.

La conexión entre el escribir para un vasto público y la amplitud de los temas tratados es manifiesta. En ese sentido tiene Feijóo dentro del ensayismo hispánico la misma significación que Addison en el británico, por esa calidad vulgarizadora suya. El propósito del ensayista inglés, al fundar The Spectator, era el de trasladar la filosofía a las tertulias de los cafés, popularizar, vulgarizar el saber de su tiempo. Y el público inglés respondió con el mismo entusiasmo al intento de Addison que el español al de Feijóo. El fenómeno histórico-literario estudiado por A. S. Collins en su libro Authorship in the days of Johnson, que él llama "crecimiento del público", corresponde en la historia de España a la época y a la acción de Feijóo, así como en Inglaterra es Addison quien lo inicia y representa. Tenía, pues, razón Emilia Pardo Bazán al decir que "era habilidad de Feijóo interesar a las muchedumbres". En el fondo, esta habilidad suya es la consecuencia de su actitud ante el prójimo y ante la palabra humana. Tomando como término de comparación, para aclarar esto, a su alter ego, a Fray Martín Sarmiento, se pueden sacar algunas conclusiones muy significativas. Ambos benedictinos se parecen mucho, por su amplia cultura, por su interés en las ciencias experimentales, por su actitud filosófica. Y Sarmiento escribe bien, pero es hombre de sensibilidad poco comunicativa, y, sobre todo, desprecia a la generalidad de sus semejantes. En el curiosísimo ensayo suyo, Por qué no escribo, dice tajantemente que él cree que Madrid, la flor humana de España, "está poblada por cincuenta mil idiotas", y por lo tanto no ve qué sentido tiene escribir (Semanario de Valladares, VI). Es lógico, pues, que Sarmiento dé a su prosa, en este ensayo, un aire quevedescamente fustigador, como expresión de su actitud de encerramiento. Feijóo, lo contrario en esto de su compañero de orden, es hombre de sensibilidad comunicativa y además cree en la capacidad de mejora del hombre. Su prurito reformador, su lucha contra los "errores populares", son motivados, aparte los móviles personales señalados, por una clara fe en el progreso humano en general y en el progreso del hombre español

5 Textos citados por Domínguez Bordona en su edición de las Generaciones y semblanzas, Clásicos Castellanos, 1924, pág. 223. 
en particular. De ahí que aspire a que su obra sea supremamente operante, y lo consigue, no sólo mediante la información enciclopédica, sino, sobre todo, gracias al estilo urbano y llano que le caracteriza. En los Sueños morales de Torres Villarroel le advierte a éste "Quevedo" que sus críticas corren el riesgo de ser "más buena plática que desahogo". La actividad literaria de Feijóo es, justamente, buena plática y no desahogo. Y ese su aire de buen platicador es su rasgo literario más valioso y su cualidad humana más preciada. El habla, con cierto orgullo, de los escritores que "sacrifican la pluma al bien común", y él es uno de ellos. Bien es verdad, también, que si el estilo de Feijóo fué extraordinariamente operante, no logra en cambio alcanzar la belleza literaria de un Quevedo o de un Gracián. El equilibrio entre "buena plática" y "desahogo", problema que ha de resolver todo escritor, no se da en su obra, en la que predomina siempre el "bien común" y no se atiende a lo que él también llama "interés particular". Sin embargo, Feijóo, en virtud de esas mismas limitaciones, abre nuevos caminos expresivos al ensayismo hispánico. Su norma literaria, que consiste, según él, "en usar de las locuciones más naturales y más inmediatamente representativas de los objetos", se convertirá en principio estilístico de muchos de los ensayistas que le suceden, desde Cadalso hasta Azorín, pasando por Larra y Clarín. Pudiera incluso afirmarse que en Feijóo lo que cobra, finalmente, significación literaria no son tanto sus ideas como la actitud que él representa y los principios estéticos que le guían. Quedan, en una palabra, el hombre y el método. De ahí que su influencia, dentro de la literatura de ensayos, haya sido superior a los méritos artísticos y al contenido ideológico de su obra. Intentó forjarse un estilo que fuera expresión única de su propia personalidad y lo logró. Al realzar en su manera de expresarse la buena plática y no el desahogo, crea lo que llamaríamos "prosa general" del siglo xvir. $Y$ si sus escritos, a fuerza de ser temporalmente operantes, han perdido valor eterno, el impulso personalizante que le caracteriza le ha salvado a él, le ha creado a sí mismo: Fray Benito, el Reformador de las Españas.

Juan López Marichal

Harvard University. 